\title{
Exclusive breastfeeding up to six months: Are we getting the right figures?
}

\author{
Priyanka Gunasekara ${ }^{1}$, G A Asha Lakmali², Sujeewa Amarasena ${ }^{3}$, *Manjula Hettiarachchi ${ }^{4}$
}

Sri Lanka Journal of Child Health, 2018; 47(4): 311-315

\begin{abstract}
Introduction: Exclusive breastfeeding (EBF) is recommended up to six months of age and is usually estimated by the 24-recall method which actually overestimates the real rate. EBF rate in Sri Lanka up to 4 months of age is $75 \%$ and up to 6 months of age is $51 \%$ according to data of the Sri Lanka Demographic \& Health Survey 2006/07. Deuterium oxide dose-to-mother technique could be utilised for assessment of intake by babies of breastmilk as well as intake of water from sources other than breastmilk.
\end{abstract}

Objective: To determine the actual EBF rates at 3 and 6 months of age of infants in Sri Lanka using deuterium oxide dose-to-mother technique.

Method: Thirty healthy mother-infant dyads were followed up for a six month period from birth and breast milk intake was measured at 3 and 6 months using deuterium isotope analysis. Further, an interviewer administered questionnaire asked about the feeding history.

Results: The average milk intake at 3 months was $772 \pm 134 \mathrm{~g} /$ day $^{1}$ (range 587-1057) and 800 \pm 174 $\mathrm{g} /$ day $^{1}$ (range $500-1113$ ) at 6 months $(p=0.30)$. The non-milk oral intake at 3 months was $91 \pm 45 \mathrm{~g} /$ day $^{1}$ (range -2-166) and $128 \pm 63 \mathrm{~g} /$ day $^{1}$ (range 25-304) at 6 months $(\mathrm{p}=0.01)$. Breastfeeding practices revealed that only $40 \%(n=12)$ of mothers at 3 months and $30 \%(n=9)$ of mothers at 6 months were practising EBF. It confirmed that the EBF rate

\footnotetext{
${ }^{1}$ Medical Officer, Teaching Hospital Karapitiya, Sri Lanka, ${ }^{2}$ Medical Officer of Health, Bope Poddala, Sri Lanka, ${ }^{3}$ Senior Professor, ${ }^{4}$ Professor, Faculty of Medicine, University of Ruhuna, Sri Lanka.

*Correspondence: manjulah@med.ruh.ac.lk
}

(Received on 26 December 2017: Accepted after revision on 16 February 2018)

The authors declare that there are no conflicts of interest

The study received funds from the International Atomic Energy Agency project titled 'Using stable isotope techniques to monitor situations and interventions for promoting infant and young child nutrition' (IAEA/RAS/6/073) and Ministry of Health (ETR/M/MC/0939/2015), Sri Lanka.

Open Access Article published under the Creative

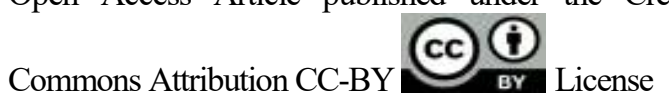

among study subjects was $50 \%$ at 3 months and $27 \%$ at 6 months, with the cut-off of $82.5 \mathrm{~g} /$ day $^{1}$ of non-milk oral intake.

Conclusions: A decrease in EBF was noted between 3 and 6 months using deuterium oxide dose-to-mother technique. Further, the EBF rates in this study sample are much lower than the presently reported value for Sri Lanka using recall method.

DOI: http://dx.doi.org/10.4038/sljch.v47i4.8591

(Key words: Exclusive breastfeeding, deuterium oxide dose-to-mother, milk intake, non-milk oral intake, body composition, fat mass)

\section{Introduction}

World Health Organization recommends exclusive breastfeeding (EBF) for the initial six months of life, followed by appropriate complementary foods and continuing breastfeeding till two years of age to achieve optimal growth, development and health ${ }^{1}$. Multiple studies have been conducted on the macro- and micro-nutrient composition of human milk throughout the different stages of lactation at various geographical, ethnic and socioeconomic settings across the globe ${ }^{2,3}$. However, there is very little information on the quantity of breastmilk consumed by infants, especially in developing countries ${ }^{4}$.

Accurately measuring EBF duration is complicated by factors associated with definitions, timing, recall duration, analytic methods and sample bias ${ }^{5}$. The deuterium oxide dose-to-mother technique is more accurate than the conventional methods, can be applied in the field setting and is safe for both mother and baby ${ }^{4}$. In this technique most of the non-deuterated water percentage is equal to the additional liquid intake of the infant.

\section{Objective}

To determine the actual EBF rates at 3 and 6 months of age of infants in Sri Lanka using deuterium oxide dose-to-mother technique.

\section{Method}

Randomly selected 30 mother-baby pairs with mothers' age $<40$ years, following the $1^{\text {st }}, 2^{\text {nd }}$ or $3^{\text {rd }}$ pregnancy with a healthy term single baby were recruited for the study. Study protocol was approved by the Ethical Review Committee of the Faculty of Medicine, University of Ruhuna, Sri Lanka, and institutional approvals were obtained 
from the Ministry of Healthcare and Nutrition and the Regional Director of Health Services, Galle. Inclusion criteria were mothers of 18-40 years of age, no more than 3 parities and having term baby (37-40 weeks) and who would practise ERF for 6 month period. Twin or pre-term or babies with complicated deliveries were excluded. Written informed consent was obtained from the mothers after explaining the procedures, expected outcomes, and the value of the research. The questionnaire on EBF was administered to be validated against the deuterium dose to mother method to assess breast milk intake of babies aged 3 and 6 months among participating countries. The sample of 30 mother-baby dyads can detect a difference in the proportion of true non-exclusive breastfeeding mothers (EBF defaulters) of 0.6. For example, if the proportion of defaulters by questionnaire is $<0.1$ and proportion of defaulters by dose to mother is 0.7 , the sample of 30 will suffice to demonstrate a significant difference. Basal saliva samples (by asking the mother to roll sterile cotton wool under the tongue for 1-2 minutes until the cotton is soaked with saliva and placing a sterile cotton wool under the baby's tongue using a stick for about 30-40 seconds) and anthropometry were taken from both prior to dosing with deuterium oxide $\left(\mathrm{D}_{2} \mathrm{O}\right)$ to the mother (i.e. day 0 ). Soaked swab/ cotton wool was placed in a $10 \mathrm{ml}$ syringe under hygienic conditions and expressed into the vial to obtain $1 \mathrm{~mL}$ of saliva in duplicate. Once the basal saliva sample was collected, an oral dose of $30 \mathrm{~g}$ deuterated water (i.e. $\mathrm{D}_{2} \mathrm{O}$ ) was administered to mother. Then further saliva samples were collected (post-dose) on days 1, 2, 3, 4 and 13, 14, from both mother and infant. Samples were frozen at $-80^{\circ} \mathrm{C}$, stored, and transported to the USDA/Agricultural Research Service Children's Nutrition Research Centre at
Baylor College of Medicine in Houston, Texas, for isotope analysis.

Intake of breast milk was calculated following the method described previously ${ }^{6}$. Curves were generated using data obtained from isotope levels of saliva samples and the time elapsing after administering $\mathrm{D}_{2} \mathrm{O}$ to mothers, to reflect the disappearance of isotope from mothers' body water and its appearance and disappearance from infants' body water. The curves were fitted to the equations using the Solver function of Microsoft Excel. From the fitted curves, information regarding the mother's body composition and daily water intake was determined. This methodology calculates the mean breast milk intake over a 2 -week period.

Major/primary outcome variable of study was the proportion of infants exclusively breastfed. Secondary outcome variables were volume of breast milk intake and non-milk oral intake. Data on two-time points (3 and 6 months) were confirmed with normal distribution and compared with paired t-test and any result was considered as significant at 5\% level of significance. Microsoft Excel 2016 was used for data entry and analysis.

\section{Results}

The age of mothers at 3-months lactation was $29.8 \pm 4$ years. Ten mothers were from first pregnancy, 15 on their second baby and the remainder $(n=5)$ had 2 live births on earlier occasions. Only 3 mothers were employed, and they were on maternity leave during study period (i.e. 6 months). The mean birth weight and mean weights at 3 and 6 months of study subjects were $2.9 \pm 0.4 \mathrm{~kg}, \quad 5.3 \pm 0.7 \mathrm{~kg}, \quad 6.5 \pm 0.7 \mathrm{~kg}$ respectively. Kinetic data of infants and mothers based on the deuterium oxide-to-the-mother model are shown in Table 1. 
Exclusive breastfeeding up to six months: Are we .... Sri Lanka Journal of Child Health, 2018; 47(4): 311-315

Table 1: Kinetic data of the mothers and infants based on the deuterium-oxide-to-the-mother model ( $n=30)$

\begin{tabular}{|c|c|c|c|}
\hline Kinetic data (unit) & $\begin{array}{c}3 \text { months } \\
M e a n \pm S D\end{array}$ & $\begin{array}{c}6 \text { months } \\
M e a n \pm S D\end{array}$ & $p$ value ${ }^{*}$ \\
\hline \multicolumn{4}{|l|}{ Mother } \\
\hline Deuterium dilution space $(\mathrm{kg})$ & $30.6 \pm 4.5$ & $30.9 \pm 4.4$ & 0.45 \\
\hline Total body water $(\mathrm{kg})$ & $29.4 \pm 4.3$ & $29.7 \pm 4.2$ & 0.45 \\
\hline Fat-free mass (kg) & $40.2 \pm 5.9$ & $40.6 \pm 5.7$ & 0.45 \\
\hline Body fat (kg) & $14.0 \pm 6.0$ & $13.1 \pm 6.5$ & 0.08 \\
\hline Fat mass (\%) & $24.9 \pm 7.0$ & $23.2 \pm 8.4$ & 0.08 \\
\hline \multicolumn{4}{|l|}{ Infant } \\
\hline Human milk intake $\left(\mathrm{g} \cdot \mathrm{d}^{-1}\right)$ & $770 \pm 140$ & $803 \pm 170$ & 0.22 \\
\hline Water input from milk $\left(\mathrm{g} \cdot \mathrm{d}^{-1}\right)$ & $740 \pm 130$ & $772 \pm 170$ & 0.22 \\
\hline Water used in growth $\left(\mathrm{g} . \mathrm{d}^{-1}\right)$ & $10 \pm 4$ & $5 \pm 6$ & $<0.001$ \\
\hline Total water output $\left(\mathrm{g} . \mathrm{d}^{-1}\right)$ & $878 \pm 140$ & $956 \pm 180$ & $<0.001$ \\
\hline Non-oral water intake (g.d $\left.\mathrm{d}^{-1}\right)$ & $57 \pm 10$ & $61 \pm 10$ & 0.04 \\
\hline Non-milk oral intake $\left(\mathrm{g} . \mathrm{d}^{-1}\right)$ & $94 \pm 40$ & $129 \pm 60$ & 0.01 \\
\hline **Square root MSE $\left(\mathrm{mg} / \mathrm{kg}^{-1}\right)$ & 12.065 & 8.720 & 0.22 \\
\hline
\end{tabular}

*Based on t-test: paired two sample for means at probability level of 0.05

${ }^{*}$ MSE is the square of the differences between the measured and predicted deuterium enrichment in the mother and in the infant. The differences are squared to get rid of negative values. The square root of the sum of the MSE of the mother and the MSE of the infant represents the total error of the model and reflects how well the data are fitting the model.

No significant difference was found in any kinetic parameter on maternal body composition. In the infant, human milk intake and the water input from milk was not different at the two intervention points. However, the non-milk (oral) intake and non-oral water intake significantly increased with age ( $\mathrm{p}=0.04$ and $\mathrm{p}=0.02$ respectively). The square root of the mean square error (expressed as $\mathrm{mg} / \mathrm{kg}^{1}$ ) of the model was very small, indicating a good fit of data to the model.

Information on the breastfeeding practices revealed that only $40 \%(n=12)$ at 3 -months and $30 \%(n=9)$ of mothers at 6 -months were practising EBF. The other mothers ( $\mathrm{n}=18$ at 3 -months and 21 at 6months) admitted giving either water or water with sugar or formula during this period. The average milk intake at 3 -months was $772 \pm 134 \mathrm{~g} /$ day $^{1}$ (range $587-1057$ ) and $800 \pm 174 \mathrm{~g} /$ day $^{1}$ (range $500-1113$ ) at 6 -months $(\mathrm{p}=0.30)$ respectively. The non-milk oral intake at 3 -month was $91 \pm 45 \mathrm{~g} /$ day $^{1}$ (range -2 -166 ) and $128 \pm 63 \mathrm{~g} /$ day $^{1}$ (range $25-304$ ) at 6months respectively $(p=0.01)$. When the cut-off of $82.5 \mathrm{~g} /$ day $^{1}$ of non-milk oral intake applied we found that the EBF rate among study subjects were $50 \%$ at 3 -months $(n=15)$ and $27 \%$ at 6 -months $(n=8)$ respectively (Figure 1$)$.
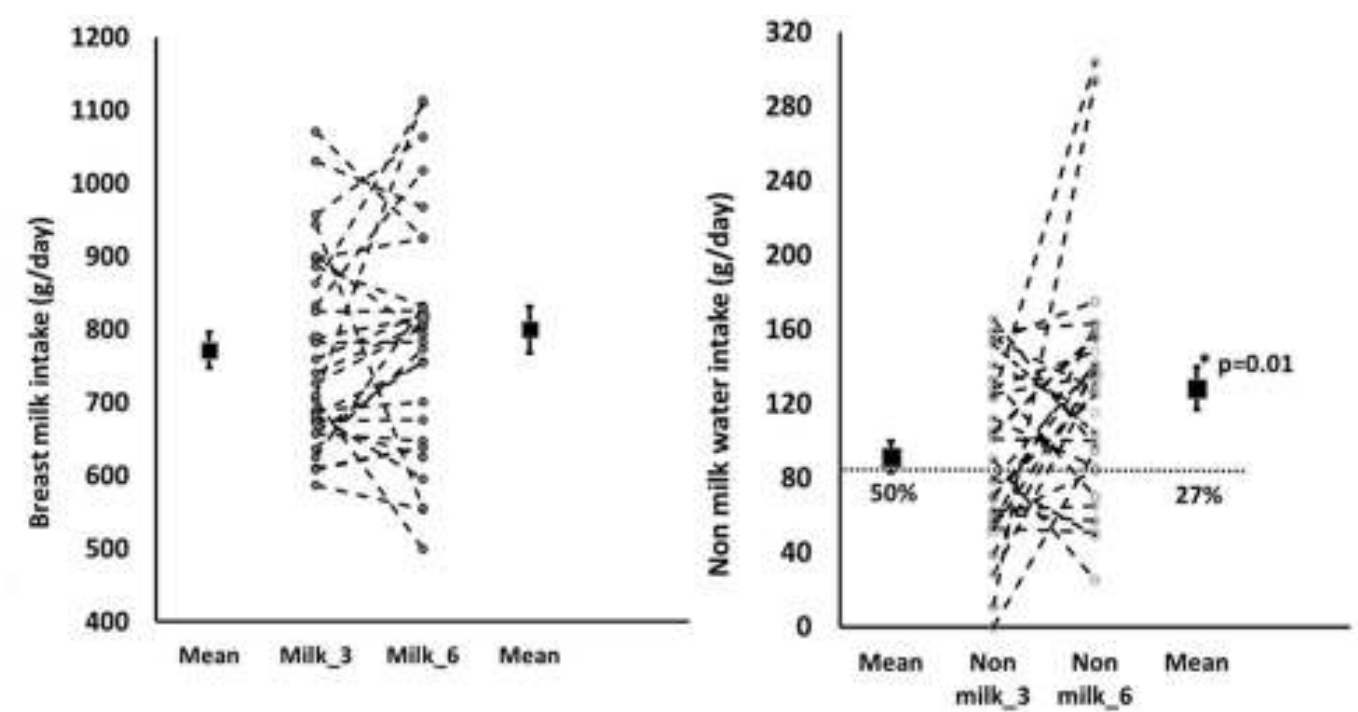

Figure 1: Breast milk intake at 3 months and 6 months anong each stuh participant (left panei) and nonmilk oral intake (right panel) using deuteriun isotope analysis

"The dash line in right panel indicates the cut-off value $\left(82.5 \mathrm{~g} \cdot \mathrm{d}^{-1}\right)$ for non-milk oral intake. The Mean \pm SEM was indicated at each investigation point.

Breastmilk intake was unaffected by mother's age at delivery $(p=0.13)$, parity $(p=0.50)$, body weight $(p=0.69)$, body mass index $(p=0.26)$, fat free mass $(p=0.72)$, or $\%$ fat mass $(p=0.80)$. However, milk 
intake was positively associated with baby's weight $(\mathrm{p}=0.01, \mathrm{r}=0.59)$ at 3 months of lactation. Milk intake was also positively related to baby's age $(p=0.001, r=0.57)$ and negatively to mother's age $(\mathrm{p}=0.03, \mathrm{r}=-0.40)$ at 6 months of lactation.

\section{Discussion}

This is the first ever longitudinal study to assess the breastfeeding during the recommended period of six months of life among infants in Sri Lanka. The average breast milk intake at 3 and 6 months of life is comparable with previously published data from elsewhere ${ }^{7,8}$. In a previous study we reported that the EBF rate for first 6 months among Sri Lankan mothers was $49.0 \%$, based on mother's recall ${ }^{9}$. When a lactating mother drinks a dose of $\mathrm{D}_{2} \mathrm{O}$ which is distributed throughout her body in a short time (incorporated into her milk), baby receives $2 \mathrm{H}$ only during breast-feeding. Saliva of both mother and child is enriched with $2 \mathrm{H}$ which can be measured by an isotope ratio mass spectrometer and the alterations in isotope concentration show the amount of breast milk consumed by baby and whether baby has consumed water from other sources. With this objective assessment we were able to reveal the actual EBF rate to be $27 \%$ at 6 months in this group of mothers.

Deuterium is a naturally occurring stable isotope of hydrogen. It does not decay or emit any harmful radiation as compared to radioactive isotopes such as tritium or carbon-14. Deuterium has a natural abundance of $0.0156 \%$ and is found in our body tissues (in a $50-\mathrm{kg}$ adult, there is approximately $1.5 \mathrm{~g}$ of deuterium). Numerous studies have been carried out using deuterium to measure energy expenditure, body composition and breast milk consumption in thousands of premature infants, new-borns, toddlers, adolescents, pregnant teens, pregnant and lactating women, and older minority women with no adverse effects ${ }^{4}$.

The WHO recommended EBF definition is based on 24-hour dietary recall and can be used only for infants of 0-6 months old. This is the method used in the Sri Lanka Demographic and Health Survey and is the basis of the reported EBF rate of $75 \%$ in Sri Lanka ${ }^{10}$. 24-hour recall method over-estimates EBF prevalence as the data are based only on feeding practices for the day previous to the survey. Infants infrequently given liquids or foods, but not given during the day prior to the survey, are classified as exclusively breastfed. Labbock defined EBF rate as "the proportion of infants less than six months of age who received only breast milk". For this definition, either it must be a cohort study, or the investigator must obtain a detailed history of feeding practices from the time of birth ${ }^{11}$. The since-birth recall methods also overestimated EBF rates because of the difficulty in correctly remembering practices occurring long ago. Further, previous studies revealed that mothers' own recall of EBF overestimates it by around $40 \%$ at 3-6 months of age ${ }^{12}$.

Our results agree with the reported values on mean human milk intake of well-nourished mothers $\left(\sim 700-800 \mathrm{~g} / \mathrm{day}^{1}\right)$. Further, we believe that the mothers in this study have answered truthfully as they knew that it will be checked biochemically. We recruit subjects with a written agreement of EBF for 6 months period. Yet, they did not comply with such assurance. Excessive crying of baby and pressure from other family members (i.e., grandmother, father or relative of the baby) are the main excuses given by mothers who initiate feeding other than breast milk during this period. This fact raises concerns regarding the accuracy of high EBF rates based on maternal recall collected in surveys. Mothers may be giving other fluids without admitting it in routine surveys in fear of being reprimanded by health care workers.

We suggest conducting objective assessments using deuterium to mother technique to be used in conjunction with routine surveys to assess EBF rates accurately while consolidating and reviewing present breastfeeding promotion and education programmes at least in selected areas.

\section{Conclusions}

A decrease in EBF was noted between 3 and 6 months using deuterium oxide dose-to-mother technique. Further, the EBF rates in this study sample are much lower than the presently reported value for Sri Lanka using recall method.

\section{Acknowledgements}

We thank all mothers and babies participating in study, the pre-intern medical officers attached to the Nuclear Medicine Unit (Dilini Ratnayake and Sanduni Apsara) for their assistance in sample collection and technical staff of the Children's Nutrition Research Centre, Department of Pediatrics, Baylor College of Medicine, Houston, Texas, USA for sample analysis.

\section{References}

1. The World Health Organization's infant feeding recommendation. Available from: http://www.who.int/nutrition/topics/infantf eeding_recommendation/en/

2. Jihong Q, Tongxin C, Weiming L, Shengmei W, Jianxing Z. Breast milk macro- and micronutrient composition in lactating mothers from suburban and urban Shanghai. Journal of Paediatrics and Child Health 2010; 46:115-20. 
3. Kulski JK, Hartmann PE. Changes in human milk composition during initiation of lactation. Australian Journal of Experimental Biology and Medical Science 1981; 59(1):101-14.

4. International Atomic Energy Agency. IAEA Human Health Series No.7. Stable isotope techniques to assess intake of human milk in breastfed infants Vienna: IAEA; 2010

5. Greiner T. Exclusive breastfeeding: measurement and indicators. International Breastfeeding Journal 2014; 9: 18.

6. Bandara $\mathrm{T}$, Hettiarachchi $\mathrm{M}$, Liyanage $\mathrm{C}$, Amarasena S, Wong WW. The deuterium oxide to the mother method documents adequate breast-milk intake among Sri Lankan infants. Journal of Nutrition 2015; 145:1325-9.

7. Choua G, Kari K, Haloui N, Slater C, Aguenaou H, Mokhtar N. Quantitative assessment of breastfeeding practices and maternal body composition in Moroccan lactating women during six months after birth using stable isotopic dilution technique. Indian Journal of Maternal and Child Health 2013; 1:45-50.

8. Moore SE, Prentice AM, Coward WA, Wright A, Frongillo EA, Fulford AJC, et al. Use of stable-isotope techniques to validate infant feeding practices reported by Bangladeshi women receiving breastfeeding counseling. American Journal of Clinical Nutrition 2007; 85:1075-82.
9. Bandara T, Hettiarachchi M, Liyanage C, Amarasena S. Current infant feeding practices and impact on growth in babies during the second half of infancy. Journal of Human Nutrition and Dietetics 2015; 28: $366-74$.

10. Department of Census and Statistics. Sri Lanka Demographic and Health Survey 2006/7 Preliminary Report. Department of Census and Statistics In collaboration with Ministry of Healthcare and Nutrition. Colombo, 2008.

11. Agampodi SB, Fernando S, Dharmaratne SD. Comparison of definitions used for Exclusive Breast Feeding-The Labbock's strict definition and the WHO definition as methods of estimating exclusive breastfeeding rates in Sri Lanka. Ceylon Medical Journal 2009; 54 (suppl 1):20.

12. Owino VO, Slater C, Loechl CU. Using stable isotope techniques in nutrition assessments and tracking of global targets post-2015. Proceedings of the Nutrition Society 2017; 76:495-503. 